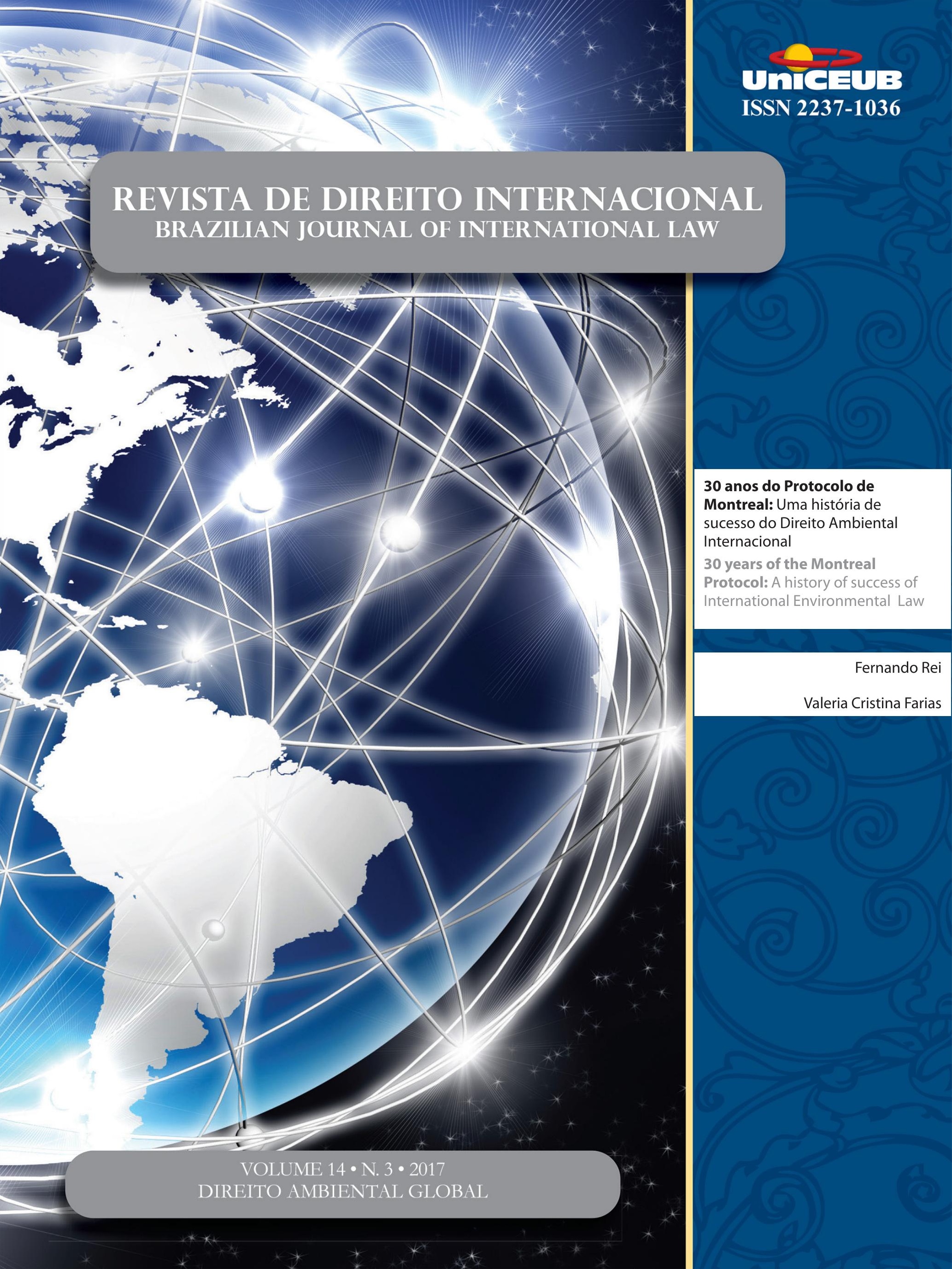




\section{Sumário}

I. Crônicas do Direito Internacional ...............................................1

CRÔNICAS DE DiREITO INTERNACIONAL PÚBLICO ........................................................................ 3

A política australiana de Refúgio e a decisão da Suprema Corte de PAPUA NOVA GUINÉ: A

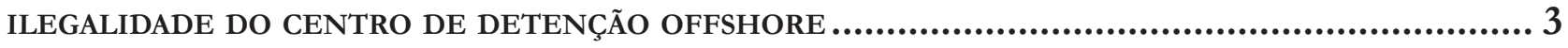

Tarin Cristino Frota Mont'Alverne e Ana Carolina Barbosa Pereira Matos

II. Dossiê especial: Direito Ambiental Global............................................ 7

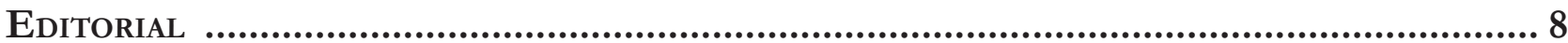

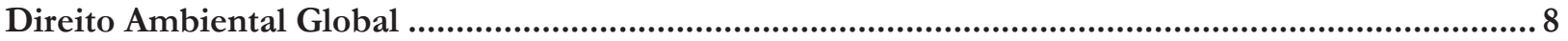

Priscila Pereira de Andrade

Direito Global: UMa TEORIA ADEQUAda PARA SE PENSAR o DiREITO AMBIENTAL? ................10 Arnaud Van Waeyenberge

“Complex is Beautiful": What role for the 2015 Paris Agreement in making the Effective Links within the Climate Regime Complex? .................................................21 Sandrine Maljean-Dubois e Matthieu Wemaëre

UNE ILLUSTRATION DU DROIT GLOBAL, LA LEX MERCATORIA CLIMATIQUE...............................31 Mathilde Hautereau-Boutonnet

OCÉANS ET CHANGEMENTS CLIMATIQUES : RECHERCHER LES INTERACTIONS AU SEIN DE LA FRAGMENTATION DU DROIT INTERNATIONAL

Sophie Gambardella

Une gouvernance globale du Climat par la transparence depuis l'Accord de Paris: Le DROIT GLOBAL DE L'ENVIRONNEMENT COMME SOLFÈGE? .56

Anne-Sofie Tabau 
LA PROGRESSIVE HARMONISATION DES RÈGLES DU PROCÈS ENVIRONNEMENTAL: MANIFESTATION

DE L'ÉMERGENCE D'UN DROIT GLOBAL? ............................................................69

Eve Truilhé-Marengo

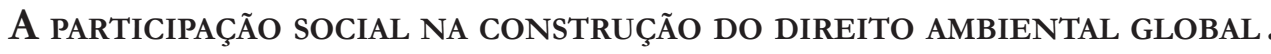
80 Michelle Lucas Cardoso Balbino

A PROTEÇÃo AMBIENTAL COMO EFEITO INDIRETO DO SISTEMA DE GESTÃo DE ENERGIA ISO 50001

Matheus Linck Bassani e Ricardo Serrano Osorio

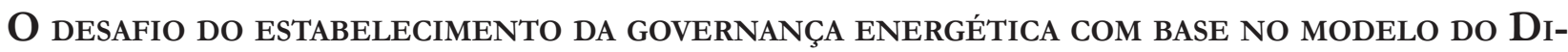
reito Administrativo Global: ESTUdo de CASO DAS ENERgias RENOVÁveis. 122 Alice Rocha da Silva

Othon Pantoja Oliveira de Azevedo

O PRINCÍPIO DA PARTICIPAÇÃo E A CRIAÇÃO E GESTÃo DAS ÁREAS PROTEGIDAS NA PERSPECTIVA DO DIREITO AMBIENTAL GLOBAI

Marcia Dieguez Leuzinger e Solange Teles da Silva

A teoria Ambientalista (GREen theOry) e a COMpetênCia CONSUltiva da CoRTE InTERAmericana de Direitos Humanos: O caso da Colômbia................................................. 148

Eduardo Biacchi Gomes e Ane Elise Brandalise

III. Artigos sobre outros temas....................................................... 160

30 anos do Protocolo de Montreal: Uma história de sucesso do Direito Ambiental

INTERNACIONAL 162

Fernando Rei e Valeria Cristina Farias

MinORIAS NACIONAIS, PROTEÇão INTERNACIONAL E TRANSNACIONALIDADE 182 Ana Maria D'Ávila Lopes e Luis Haroldo Pereira dos Santos Junior

Da relevância dos casos do Desarmamento Nuclear perante a Corte Internacional DE JUSTIÇA 203 Lucas Carlos Lima 
OS CONTROLES DE CONVENCIONALIDADE TRADICIONAL E INTERAMERICANO: INSTITUTOS DISTINTOS OU DUAS FACES DA MESMA MOEDA?

Gilberto Schäfer, Roger Raupp Rios, Paulo Gilberto Cogo Leivas e Jesus Tupã Silveira Gomes

EL SOFT LAW COMO FUENTE DEL DERECHO INTERNACIONAL: REFLEXIONES DESDE LA TEORÍA DE LA COMPLEJIDAD

Rafael Sanz e André Folloni

Ley de rotulación de alimentos de Chile: ¿'Traba comercial o protección de la saLUD?

Nicolás Cobo

IV. RESENHA DE LIVRO.

O CiVILIZAdor gentil das AmÉRICAS: CONSIDERAÇÕes EM TORNO DA OBRA THE HIDDEN HIStory of International LaW in the Americas: Empire and LeGal Networks, de Juan Pablo SCARFI 278

Cicero Krupp da Luz

'Mestizo International Law: A global intelectual history 1842 - 1933' De Autoría de Arnulf Becker-Lorca .283 Jimena Sierra-Camargo

América Latina em Continuidades e rupturas 287 Adriane Sanctis 


\title{
30 anos do Protocolo de Montreal: Uma história de sucesso do Direito Ambiental Internacional*
}

\author{
30 years of the Montreal Protocol: A history of \\ success of International Environmental Law
}

\author{
Fernando Rei** \\ Valeria Cristina Farias***
}

\section{Resumo}

A descoberta científica da destruição da camada de ozônio e seus efeitos à saúde humana, plantas e animais, desencadeou o enfrentamento global do problema e as tratativas internacionais sinalizaram a construção de um regime jurídico internacional, iniciado com a Convenção de Viena para a Proteção da Camada de Ozônio, de 1985, e aperfeiçoado com o Protocolo de Montreal sobre as Substâncias que Destroem a Camada de Ozônio, que completou 30 anos. Atualmente, o comércio de substâncias que destroem a camada de ozônio teve que ser reduzido em todo o planeta, seguindo-se cotas pré-definidas e desenvolvendo-se tecnologias alternativas para reduzir ou eliminar os riscos à camada de ozônio. O presente artigo, que utilizou o método dedutivo, por meio de pesquisa bibliográfica e documental, pretende analisar o regime jurídico do ozônio, com destaque ao exercício da governança instaurado, que permitiu uma participação ampliada e proporcionou o encontro de alternativas seguras ao enfrentamento do problema, destacando-se a contribuição para o Direito Ambiental Internacional, como exemplo de tutela participativa e eficiente. Ressalta-se, no entanto, que uma boa parte das substâncias alternativas adotadas no Protocolo de Montreal não agridem o ozônio, mas intensificam o aquecimento global, recomendando uma sinergia entre os regimes internacionais. A conclusão do trabalho é que a arquitetura do regime de ozônio, por meio de protocolo restritivo, pode ser uma alternativa ao regime internacional de mudança climática, idealizando-se emendas dinâmicas e flexíveis, capazes de ajustar interesses econômicos e ambientais, na busca da eficiência que é tão tormentosa no controle do clima.

Palavras-Chaves: Camada de Ozônio - Protocolo de Montreal - SDOs Mudanças Globais.

Fundação Armando Alvares Penteado - FAAP; Professor do Programa de Doutorado em Direito Ambiental Internacional da Universidade Católica de Santos; Diretor Científico da SBDIMA (Sociedade Brasileira de Direito Internacional do Meio Ambiente). E-mail: fernandorei@ig.com.br.

*** Procuradora do Estado de São Paulo, Professora de Direito da Universidade Paulista (UNIP) e Escola Superior de Administração, Marketing e Comunicação (ESAMC). E-mail: vfarias@sp.gov.br.
* Recebido em 04/06/2017

Aprovado em 18/12/2017

** Professor Titular de Direito Ambiental da

\section{Abstract}

The scientific discovery of the destruction of the ozone layer and its effects on human health, plants and animals, triggered the global confrontation of the problem and the international negotiations signaled the construction of an international legal regime, initiated with the Vienna Conven- 
tion for the Protection of the Layer Ozone Layer, 1985, and improved with the Montreal Protocol on Substances that Deplete the Ozone Layer, which turns 30. Currently, trade in ozone-depleting substances has had to be reduced across the globe, followed by pre-defined quotas and developing alternative technologies to reduce or eliminate the risks to the ozone layer. This article, which used the deductive method, through bibliographical and documentary research, intends to analyze the legal regime of ozone, with emphasis on the exercise of governance established, which allowed an expanded participation and provided the meeting of safe alternatives to face the problem, Highlighting the contribution to International Environmental Law, as an example of participatory and efficient protection. It should be noted, however, that a large proportion of the alternative substances adopted under the Montreal Protocol do not attack ozone, but they intensify global warming and recommend synergy between international regimes. The conclusion of the work is that the architecture of the ozone regime, through a restrictive protocol, can be an alternative to the regime of climate change, idealizing dynamic and flexible amendments, capable of adjusting economic and environmental interests, in search of the efficiency that is so stormy in the climate control.

Keywords: Ozone Layer - Montreal Protocol - ODS - Global Changes.

\section{INTRODUÇÃo}

A camada de ozônio contém $90 \%$ do ozônio do mundo e é encontrada de 15 a $55 \mathrm{~km}$ acima da superfície terrestre, na chamada estratosfera inferior. O ozônio é uma forma triatômica de oxigênio, porque se compõe de três átomos de oxigênio em vez de dois e sua formação decorre de um processo natural nos níveis superiores da atmosfera terrestre, por meio da radiação ultravioleta do sol. No entanto, assim como as radiações solares são responsáveis pela criação da camada de ozônio, por ser uma molécula instável, o ozônio, também, é destruído pela própria radiação solar ${ }^{1}$.

1 SECRETARIA DO MEIO AMBIENTE DO ESTADO DE SÃO PAULO. Entendendo o Meio Ambiente: Convenção de Viena para a Proteção da Camada de Ozônio e Protocolo de Montreal sobre Substâncias que Destroem a Camada de Ozônio. Volume V. São Paulo, 1997, p. 04.
Embora seja um gás venenoso e poluente, na estratosfera, quando forma a camada de ozônio, funciona como um escudo protetor que absorve a maioria da nociva radiação solar ultravioleta $\mathrm{B}$ (UV-B) e sem ela os raios UV-B atingiriam, diretamente, a superfície terrestre, com consequências desastrosas ${ }^{2}$.

Há, aproximadamente, quarenta e cinco anos, cientistas descobriram que alguns compostos feitos pelo homem contribuíam para a destruição da camada de ozônio. À época esses compostos químicos eram amplamente usados em muitos processos industriais e agrícolas, praticamente a partir da produção por três grandes empresas multinacionais: a Dupont de Nemours (Estados Unidos), ICI (Reino Unido) e Atochem $(\text { França })^{3}$. Alguns desses produtos químicos, a base de cloro e bromo, estavam presentes em itens do dia a dia doméstico de qualquer cidadão, como copos de espuma de isopor, refrigeradores, desodorantes em spray ${ }^{4}$.

Em 1973, dois cientistas da Universidade da Califórnia (Irvine), Frank Sherwood Rowland e Mario Molina ${ }^{5}$, iniciaram estudos sobre os impactos dos clorofluorcarbonos (CFCs) na atmosfera terrestre e descobriram que as moléculas de clorofluorcarbonos (CFC) eram suficientemente estáveis para permanecer na atmosfera até atingir o meio da estratosfera onde, finalmente, após uma média de 50 a 100 anos, seriam "quebradas" pela radiação UV, liberando um radical de cloro no processo, conhecido como "radical livre", responsável pela destruição da camada de ozônio ${ }^{6}$.

2 SARRO, Vanessa Martins. Os Mecanismos da Governança Global para Proteção da Camada de Ozônio. Dissertação apresentada para obtenção do Título de Mestre em Direito pela Universidade Católica de Santos. Santos: Universidade Católica de Santos, 2016, p. 26-26.

3 RUIZ, J.J. "Protection of the Atmospheric Environment by International Law". In: KISS, A. Ch. Y Shelton. D (Ed), Manual of European Environmental Law, 2nd.edition, Cambridge: Cambridge University Press, 1997

4 SECRETARIA DO MEIO AMBIENTE DO ESTADO DE SÃO PAULO. Entendendo o Meio Ambiente: Convenção de Viena para a Proteção da Camada de Ozônio e Protocolo de Montreal sobre Substâncias que Destroem a Camada de Ozônio. Volume V. São Paulo, 1997, p. 05.

5 O relatório decorrente desse estudo lhes renderia o Prêmio Nobel de Química, em 1995 (Press Release: The ozone layer - The Achilles heel of the biosphere. Disponível em https://www.nobelprize.org/nobel_prizes/chemistry/laureates/1995/press.html. Acesso 20 mai 2017).

6 REI, F.C.F., CARVALHO, S.M. (no prelo). O Protocolo de Montreal sobre substâncias que destroem a camada de ozônio. Coleção Embrapa de Direito Ambiental. Volume 3. 
Parte do cloro estratosférico é proveniente de fontes naturais como vulcões e espuma do oceano, reforçando-se a ideia de que a formação e destruição da camada de ozônio é um dinamismo natural dependente e responsável pelo próprio equilíbrio ambiental, mas, a par do processo natural de formação e destruição, uma boa parte do cloro estratosférico passou a ser resultante de atividades antropogênicas, decorrentes da utilização de produtos e substâncias que destroem a camada de ozônio (SDOs), como assim passaram a ser conhecidas, gerando desequilíbrio e afetando o processo evolutivo natural, porque, como dito, possuem a capacidade de se infiltrar na atmosfera e na estratosfera e, devido aos altos níveis de radiação ultravioleta solar, acabam liberando átomos de cloro e bromo, que participando de uma série complexa de reações, aceleram a destruição da camada de ozônio, deixando-a mais fina ${ }^{7}$.

Uma camada de ozônio mais fina permite que mais raios UV-B atinjam a terra e o excesso de exposição aos raios ultravioletas é geralmente aceito como um fator que contribui para o desenvolvimento de câncer de pele, o envelhecimento precoce, pode provocar danos à visão e comprometer o sistema imunológico. Os raios ultravioletas também afetam as plantas, os animais, o estágio inicial de desenvolvimento de espécies aquáticas (peixes, camarões, caranguejos), e podem causar o desequilíbrio ambiental por reduzir a produtividade do fitoplâncton, responsável pela manutenção da cadeia alimentar marinha ${ }^{8}$.

Apesar da perda do ozônio ser mais severa na região Antártida ${ }^{9}$, pesquisas demonstraram que a redução da camada de ozônio ocorreu em todos os continentes,

7 SECRETARIA DO MEIO AMBIENTE DO ESTADO DE SÃO PAULO. Entendendo o Meio Ambiente: Convenção de Viena para a Proteção da Camada de Ozônio e Protocolo de Montreal sobre Substâncias que Destroem a Camada de Ozônio. Volume V. São Paulo, 1997, p. 05-06.

8 SECRETARIA DO MEIO AMBIENTE DO ESTADO DE SÃO PAULO. Entendendo o Meio Ambiente: Convenção de Viena para a Proteção da Camada de Ozônio e Protocolo de Montreal sobre Substâncias que Destroem a Camada de Ozônio. Volume V. São Paulo, 1997, p. 09-10.

9 A explicação científica para esse maior comprometimento na região Antártida são as temperaturas extremamente baixas que levam à condensação de água e ácido nítrico, formando nuvens estratosféricas polares, que intensificam o processo de afinamento da camada de ozônio (INTERGOVERNMENTAL PANEL ON CLIMATE CHANGE. Safeguarding the Ozone Layer and the Global Climate System: Issues Related to Hydrofluorocarbons and Perfluorocarbons. Cambridge: 2005. Disponível em http:/ / https:/ / www.ipcc.ch/report/sroc/.Acesso 15 mai 2017). observando-se uma variação de maior ou menor comprometimento, que segue uma lógica climática ${ }^{10}$.

O desequilíbrio no processo evolutivo do ozônio, portanto, tem sensível ligação com vários outros problemas ambientais, como a preservação da biodiversidade e as mudanças climáticas.

O presente estudo discutirá a problemática da interferência antrópica sobre a camada de ozônio e procurará explicar como essa preocupação atingiu rapidamente o contorno global, destacando-se as medidas tomadas para o enfrentamento da necessidade de redução da produção de clorofluorcarbonos (CFCs), responsável pela destruição da camada de ozônio e que se fazia presente em itens do dia a dia doméstico de qualquer cidadão, como refrigeradores, espumas plásticas, frascos de spray, entre outros.

Para tanto, serão traçados os contornos básicos que alicerçam o regime jurídico de proteção da camada de ozônio, com ênfase no Protocolo de Montreal, o primeiro tratado ambiental legalmente vinculante, para tentar identificar como ele foi capaz de, em apenas três décadas, reduzir a produção de clorofluorcarbonos (CFCs) e estabilizar o comprometimento da camada de ozônio.

No entanto, será possível verificar que, embora considerado um dos instrumentos internacionais mais eficientes, o Protocolo de Montreal conseguiu reduzir a fabricação e o uso de clorofluorcarbonos (CFCs) em nível global, mas os substitutos utilizados, como hidroclorofluorcarbonos (HCFC), perfluorocarbonos (PFC) e halocarbonetos, importantes na redução do impacto sobre a camada de ozônio, acabaram intensificando o aquecimento global, representando uma ameaça à saúde climática do planeta, o que demonstra uma sinergia entre o regime do ozônio e o das mudanças climáticas e justifica o estudo.

Nesse sentido, por meio da análise da evolução do regime jurídico do ozônio ao longo dos trinta anos de vigência do Protocolo de Montreal, procurar-se-á identificar os fatores que determinaram o seu sucesso e qual a sua importância no contexto do Direito Ambiental Internacional como exemplo de tutela eficiente, destacando-se a importância da emenda levada a efeito na $28^{\mathrm{a}}$.

10 The Nobel Prize in Chemistry 1995. Press Releasy. The ozone layer - The Achilles heel of the biosphere, 1995. Disponível em https://www.nobelprize.org/nobel_prizes/chemistry/laureates/1995/press.html. Acesso 20 mai 2017. 
Reunião das Partes, realizada em Kigali.

Para tanto, o artigo foi estruturado em quatro seções. A primeira seção analisa o Protocolo de Montreal, contextualizado na seara do regime jurídico em formação. A segunda seção trata da governança global, debruçando-se sobre o processo de formação e desenvolvimento do regime do ozônio, que comprova a importância da governança global no processo de criação e implementação do Direito Ambiental Internacional. A terceira seção defende a necessidade de sinergia entre o regime do ozônio e de mudança climática, para finalizar, na última seção, com as conclusões desse estudo.

Para o desenvolvimento da presente pesquisa, utilizou-se o método dedutivo, por meio de pesquisa bibliográfica e documental.

\section{A ImPORTÂnCIA do PROTOCOLO de Montreal COMO INSTRUMENTO MULTILATERAL PREVENTIVO DE TUTELA DA CAMADA DE OZÔNIO}

A conexão entre o uso rotineiro de produtos produzidos à base de clorofluorcarbonos (CFCs) e o risco da modificação irreversível da atmosfera terrestre fez com que a problemática de afetação da camada de ozônio rapidamente fosse percebida pelo grande público.

A mídia e grupos ambientalistas, na década de 70 , foram responsáveis por estimular a inclusão do ozônio na pauta das agendas internacionais, porque cobravam urgência na identificação e solução do problema, alçado à dimensão global ${ }^{11}$.

Em 1977, o PNUMA convocou, em Washington, uma reunião de especialistas que elaboraram o Plano Mundial de Ação para a Camada de Ozônio, acompanhando os trabalhos de pesquisa em curso ${ }^{12}$.

A hipótese de depleção do ozônio por influência antrópica, a princípio, foi recebida com descrença pelos Estados e comunidade empresarial, até porque os

11 SARRO, Vanessa Martins. Os Mecanismos da Governança Global para Proteção da Camada de Ozônio. Dissertação apresentada para obtenção do Título de Mestre em Direito pela Universidade Católica de Santos. Santos: Universidade Católica de Santos, 2016, p. 45.

12 RUMMEL-BULSKA, I. "The Protection of the Ozone Layer under the Global Framework Convention”. In: Transboundary Air Pollution. Dordrecht: Nijhoff, 1988, p. 280. estudos não eram conclusivos nesse sentido. A comunidade empresarial investiu na divulgação das incertezas científicas que pairavam sobre o tema, da dependência de CFCs para garantir o estilo de vida moderno e do alto custo que o controle sobre essas substâncias poderia acarretar, defendendo a manutenção dos padrões industriais ${ }^{13}$.

No entanto, a par da resistência internacional e da campanha empresarial, uma forte pressão da opinião pública, principalmente nos Estados Unidos, levou a uma intensa redução do consumo de aerossóis, impulsionando a primeira regulamentação interna acerca da matéria. Na ocasião, o Congresso americano autorizou a United States Environmental Protection Agency (EPA) a regulamentar o uso de qualquer substância que fosse capaz de afetar a extratosfera e na sequência do marco regulatório, em 1978, o uso de CFC foi proibido de ser utilizado como propelente para aerossóis. Seguiram a mesma linha o Canadá, que era um produtor pequeno de CFC, a Suécia, Noruega, Dinamarca e Finlândia, que eram países importadores. Essa restrição ambiental foi responsável por uma considerável queda na produção e consumo global de CFC no final da década de $1970^{14}$.

Ocorre que os Estados Unidos, embora fossem o maior, não eram os únicos produtores de CFC.

Com a proibição americana, a Comunidade Europeia passou a dominar o mercado, sem demonstrar interesse nas ações restritivas. Ao contrário, defendiam posição contrária à regulação internacional e, juntamente com outros países como Japão, União Soviética, Canadá, China, Austrália, Brasil, México, Argentina, Venezuela e Índia, aumentaram a produção e exportação desses produtos, recuperando, rapidamente, os níveis de produção e consumo que haviam sido reduzidos pelas ações tomadas pelos Estados Unidos, Canadá e demais países citados ${ }^{15}$.

13 BENEDICK, Richard Elliot. The Improbable Montreal Protocol: Science, Diplomacy, and Defending the Ozone Layer. Disponível em: http://www.ibrarian.net/navon/paper/T_H_E_IMPROBABLE_MONTREAL_PROTOCOL_SCIENCE_DIPL. pdf?paperid=3892539. Acesso em 05 jul 2017, p. 03.

14 BENEDICK, Richard Elliot. The Improbable Montreal Protocol: Science, Diplomacy, and Defending the Ozone Layer. Disponível em: http://www.ibrarian.net/navon/paper/T_H_E_IMPROBABLE_MONTREAL_PROTOCOL_SCIENCE_DIPL. pdf?paperid=3892539. Acesso em 05 jul 2017, p. 04-05.

15 BENEDICK, Richard Elliot. The Improbable Montreal Protocol: Science, Diplomacy, and Defending the Ozone Layer. Disponível em: http://www.ibrarian.net/navon/paper/T_H_E_IMPROBABLE_MONTREAL_PROTOCOL SCIENCE DIPL. 
As tratativas internacionais tendentes ao controle do CFC passaram a ser bloqueadas, por liderança da Comunidade Europeia, como estratégia de manutenção de mercado.

Defendendo ideias contrárias, Canadá, Áustria, Dinamarca, Finlândia, Nova Zelândia, Noruega, Suécia, Suíça e Estados Unidos uniram-se, formando o Grupo de Toronto ${ }^{16}$, que trabalhou arduamente, no início da década de 80, no sentido de firmar compromissos de reduções voluntárias, trocar informações e coordenar estratégicas para restrição global do CFC.

Diante da dificuldade de consenso na adoção de medidas restritivas, em 1985, a ação diplomática desses países abandonou a ideia inicial de conduzir um acordo vinculativo para restringir o uso do CFC, preferindo a formulação de um documento de natureza meramente técnica, administrativa e científica, no intuito de quebrar a resistência inicial, apostando na evolução dos debates futuramente.

Resultado desse trabalho, a Convenção de Viena para a Proteção da Camada de Ozônio, firmada em 22 de março de 1985, não estabeleceu nenhum compromisso de redução da produção e consumo de CFC, mas inaugurou a tutela protetiva multilateral, originada nos esforços de diversas nações sob os auspícios do Programa das Nações Unidas para o Meio Ambiente (PNUMA), que desde a sua criação manifestou particular interesse no enfrentamento da problemática ${ }^{17}$. Sua maior conquista foi ter conseguido instaurar a cooperação em matéria de pesquisa e monitoramento, antes mesmo que a destruição da camada de ozônio estivesse, cientificamente, provada e seus efeitos começassem a ser percebidos ${ }^{18}$.

Em setembro de 1986, a Alliance for Responsable CFC Policy, um grupo de cerca de 500 empresas ameri-

pdf?paperid=3892539. Acesso em 05 jul 2017, p. 05

16 BENEDICK, Richard Elliot. The Improbable Montreal Protocol: Science, Diplomacy, and Defending the Ozone Layer. Disponível em http://www.ibrarian.net/navon/paper/T_H_E_IMPROBABLE_MONTREAL_PROTOCOL_SCIENCE_DIPL. pdf?paperid=3892539. Acesso em 05 jul 2017, p. 06.

17 RUMMEL-BULSKA, I. "The Protection of the Ozone Layer under the Global Framework Convention”. In: Transboundary Air Pollution. Dordrecht: Nijhoff, 1988, p. 280.

18 SARRO, Vanessa Martins. Os Mecanismos da Governança Global para Proteção da Camada de Ozônio. Dissertação apresentada para obtenção do Título de Mestre em Direito pela Universidade Católica de Santos. Santos: Universidade Católica de Santos, 2016, p. 34. canas, criada em 1980 e que, desde então, trabalhou no sentido de fazer pressão política contra a regulação industrial, manifestou apoio aos controles internacionais de CFC, agigantando a importância da Convenção de Viena e causando perplexidade na Comunidade Europeia.

A explicação para tal mudança estratégica, no entanto, não tinha viés ambiental, sendo basicamente de cunho econômico, para tentar neutralizar a vantagem competitiva que as empresas internacionais (principalmente as europeias) obtiveram com as restrições internas da década de 1970.

De forma bastante inteligente, o apoio não somente estimulou a cooperação interna pela busca de alternativas ao CFC, como induziu restrições globalmente vinculativas $^{19}$.

A chamada ao debate, influenciada pela pressão da opinião pública, da mídia e órgãos ambientalistas, o peso do apoio do grupo industrial americano e o resultado das pesquisas científicas, que destacavam que a produção e o consumo de CFC haviam ultrapassado os índices registrados em $1974^{20}$, estimularam o consenso pela regulação internacional e, em 16 de setembro de 1987, foi firmado o Protocolo de Montreal sobre Substâncias que Destroem a Camada de Ozônio, com adesão inicialmente tímida, ratificado por apenas 29 países e pela então Comunidade Econômica Europeia (CEE), entrando em vigor em $1^{\circ}$ de janeiro de 1989.

Objetivamente, o Protocolo de Montreal foi o primeiro tratado ambiental legalmente vinculante, firmado com o objetivo de proteger a camada de ozônio e eliminar a produção e o consumo de substâncias responsáveis por sua destruição. As metas para os países desenvolvidos e os em desenvolvimento são diferentes, motivadas pela aplicação do princípio das responsabilidades comuns, porém, diferenciadas ${ }^{21}$, mas todos as

19 BENEDICK, Richard Elliot. The Improbable Montreal Protocol: Science, Diplomacy, and Defending the Ozone Layer. Disponível em http://www.ibrarian.net/navon/paper/T_H_E_IMPROBABLE_MONTREAL_PROTOCOL_SCIENCE_DIPL. pdf?paperid=3892539. Acesso em 05 jul 2017, p. 09.

20 BENEDICK, Richard Elliot. The Improbable Montreal Protocol: Science, Diplomacy, and Defending the Ozone Layer. Disponível em http://www.ibrarian.net/navon/paper/T_H_E_IMPROBABLE_MONTREAL_PROTOCOL_SCIENCE_DIPL. pdf?paperid=3892539. Acesso em 05 jul 2017, p. 05.

21 Preâmbulo e artigo $5^{\circ}$., inciso I, do Protocolo de Montreal. Disponível em https:// http://www.mma.gov.br/port/conama/reuniao/dir1082/ProtocoloMontrealOzonio.pdf. Acesso 20 mai 2017. 
partes assumiram compromissos de redução.

O Protocolo reconheceu, formalmente, a significativa ameaça das substâncias que destroem a camada de ozônio (SDOs) e, construído sob a então nova arquitetura de convenção quadro, permitiu aditamentos posteriores, instituindo uma abordagem de natureza absolutamente preventiva, desenvolvida por meio de mecanismo que conduz à redução e eliminação da produção e o consumo de SDOs em todo o mundo.

Sua relevância multilateral reside no fato de ter permitido a construção — ainda em formação, mas já refletindo sinais de sucesso — de uma estratégia de ação imediata que antecedeu o completo entendimento de toda a complexidade científica acerca da problemática e que permite afirmar ter sido a dinâmica responsável pelo amadurecimento do então emergente princípio da precaução, basilar do Direito Ambiental Internacional.

O documento estabeleceu obrigações específicas para garantir a progressiva redução da produção e consumo das SDOs, até que fosse obtida a total eliminação, e está estruturado ao redor de sete grupos de hidrocarbonetos halogenados que contribuem para a destruição do ozônio. Todas essas SDOs contêm cloro ou bromo e, para cada grupo dessas substâncias, o Protocolo previu um cronograma, que estabelece um "congelamento de consumo" inicial, assim como datas pré-definidas para cessação da produção e eventual eliminação dessas substâncias.

Atualmente, como corolário de instrumento indutor de conscientização ambiental, o Protocolo de Montreal é o único tratado internacional com ratificação universal, contando com a participação maciça de 197 países, o que é indício de uma conscientização ambiental global, trabalhada ao longo da existência do regime do ozônio.

O regime jurídico estabelecido foi tão eficaz que, desde que o Protocolo entrou em vigor, as concentrações atmosféricas das principais substâncias que destroem a camada de ozônio (SDOs) se estabilizaram ou foram reduzidas. A produção de SDOs, que excedia 1,8 milhão de toneladas ao ano em 1987 foi reduzida para 83.000 toneladas em 2005. Assim, a degradação da camada de ozônio foi estabilizada em 1998 e poderá voltar aos níveis anteriores a 1980, entre 2050 e $2075^{22}$. Em se

22 Disponível em:http://www.protocolodemontreal.org. $\mathrm{br} /$ eficiente/sites/protocolodemontreal.org.br/pt-br/site. php?secao $=$ noticias\&pub $=151$. Acesso 20 mai 2017. atingindo a restauração ambiental da camada de ozônio significa devolver a situação material alterada ao estado em que se encontrava antes de sofrer o dano por parte das atividades humanas, de tal forma que os recursos prejudicados e os sistemas ecológicos recuperem sua funcionalidade modificada. Para tal, poderá requerer-se a reabilitação, ainda que não total, dos elementos ambientais negativamente impactados ${ }^{23}$.

Fenômenos como a destruição da camada de ozônio estão relacionados com mudanças difíceis e inter-relacionados entre si na tecnologia, na estrutura da produção e do comércio, nos fluxos financeiros e nas relações de poder.

Nesse sentido, o sucesso da proteção à camada de ozônio é possível porque a ciência e a indústria foram capazes de desenvolver e comercializar alternativas para as substâncias destruidoras do ozônio no âmbito de uma negociação internacional legitimada pelo interesse econômico, mas estimulada pela conscientização da sociedade, que tem exigido, da indústria, procedimentos novos e produtos inovadores. Esse processo de participação social induziu o desenvolvimento de um regime amplo e capaz de promover a adaptação dos instrumentos jurídicos às necessidades reclamadas pela sociedade e pela academia, o que implicou a intensa interação entre regulamentações adotadas em diferentes níveis, assim como interações entre as iniciativas normativas dos Estados e as iniciativas de entes privados ${ }^{24}$.

Não fossem as regulações internas dos Estados Unidos e o ressentimento das empresas americanas com a perda da competitividade no mercado, talvez as tratativas multilaterais não tivessem evoluído para um acordo vinculativo.

Além disso, a estratégia da Alliance for Responsable CFC Policy, em apoiar a Convenção de Viena, foi a alavanca que faltava para uma mudança de posicionamento da Comunidade Europeia e abrandamento da resistência oposta às tratativas, contribuindo para a adoção do Protocolo de Montreal.

23 ANTEQUERA, J. Conde. Responsabilidad y restauración ambiental por riesgos del desarrollo. In: ALONSO, E. Pérez; GARCÍA, E. Arana; PACHECO, P. Mercado; MORENO, J.L. Serrano (eds). Derecho, Globalización, Riesgo y Medio Ambiente. Valencia: Tirant lo Blanch, 2012, p.498.

24 PETERS, A.; KOECHLIN, L.; FÖRSTER. T. Nonstate actors as standard setters. Cambridge: Cambridge University Press, 2009, p. 19. 
Não se pretende sustentar neste artigo que o Protocolo de Montreal resultou da conscientização global acerca da necessidade de proteger a camada de ozônio. Ao contrário, os interesses eram muito mais econômicos do que ambientais. A Comunidade Europeia e demais países como Japão e União Soviética pretendiam garantir sua posição no mercado, diante do risco de empresas americanas recuperarem o prestígio com produtos de substituição, menos impactantes ao meio ambiente.

Assim, é possível concluir que o Regime do Ozônio, afora a pressão da sociedade, evoluiu muito mais impulsionado pelos interesses econômicos do que pela certeza da necessidade da tutela. A contribuição da indústria em desenvolver substitutivos ao CFC — tão importante para o sucesso do regime - somente foi perceptível após o Protocolo ter sido firmado. Isso porque ao estabelecer metas ambiciosas de redução da produção de CFC, os instrumentos internacionais sinalizaram no mercado uma possibilidade de lucro como resultado das pesquisas científicas que seriam necessárias, estimulando a competitividade comercial, que foi indispensável para que as soluções fossem encontradas em curto espaço de tempo, muito antes do que se previra e a menor custo do que se estimara, proporcionando uma verdadeira revolução tecnológica em diversos setores da indústria ${ }^{25}$.

Não fosse a perspectiva de lucro, a rápida solução alternativa para o CFC, que foi substituído por hidroclorocarbonos (HCFC), hidrofluorcarbonetos (HFC) e perfluorocarbonos (PFC) e a redução dos custos, evitando-se a paralização da produção, talvez a indústria não tivesse se mostrado tão disposta à cooperação.

Tais pontos, no entanto, não podem e nem devem diminuir o destaque para os instrumentos utilizados pelo regime internacional em construção, que enfrentou a problemática de forma inovadora e exitosa, desenvolvendo uma estratégia de construção e implementação, onde novos atores foram relevantes no enfrentamento, entre eles grandes empresas, Organizações Não Governamentais - ONGs, a mídia, a sociedade e alguns governos subnacionais, inclusive brasileiros, peculiaridade

25 BENEDICK, Richard Elliot. The Improbable Montreal Protocol: Science, Diplomacy, and Defending the Ozone Layer. Disponível em http://www.ibrarian.net/navon/paper/T_H_E_IMPROBABLE_MONTREAL_PROTOCOL_SCIENCE_DIPL. pdf?paperid=3892539. Acesso em 05 jul 2017, p. 22. que não era comum no cenário internacional ${ }^{26}$ e acabou servindo de inspiração a outros regimes ambientais.

Nesse sentido, cabe destacar, também, a importância dos mecanismos institucionais adotados para o sucesso do regime do ozônio, como é o caso do Fundo Multilateral para a Implementação do Protocolo de Montreal (FML) e da estrutura funcional.

O Fundo Multilateral para a Implementação do Protocolo de Montreal (FML) foi instituído em 1991, por meio do Programa das Nações Unidas para o Desenvolvimento - PUND, com a finalidade de prover assistência técnica e financeira aos países em desenvolvimento com recursos provenientes dos países desenvolvidos, que vem permitindo que países em desenvolvimento possam honrar os compromissos assumidos no Protocolo de Montreal ${ }^{27}$.

Por outro lado, a estrutura institucional dos órgãos e comitês subsidiários, desenvolvidos para dar suporte técnico e administrativo às Partes, auxilia as questões relativas à conformidade, transferência de tecnologia e implementação de ações e também serviu de modelo para os acordos ambientais que se seguiram.

O caráter institucional adotado foi projetado para que o Protocolo de Montreal se tornasse um instrumento dinâmico e flexível, trabalhando com um conjunto de eliminações químicas, que permite ao mercado inovar e ajustar as ações de acordo com a necessidade e o desenvolvimento da tecnologia.

Por meio das Reuniões das Partes, podem ser adicionadas substâncias controladas adicionais por meio de emendas, bem como pode ser acelerada a eliminação de substâncias já previstas por meio de ajustes ou outras decisões baseadas em consenso. As emendas devem ser aprovadas por consenso, mas, na sua impossibilidade, admitem a aprovação por maioria de três quartos dos votos das Partes presentes e votantes na sessão, estando sujeitas a futura aceitação dos membros ${ }^{28}$. Os ajustes, por sua vez, são aprovados por consenso e entram em

26 REI, F.C.F., CARVALHO, S.M. 25 anos do protocolo de Montreal sobre substâncias que destroem a camada de Ozônio: a experiência do Brasil. Revista Juris da Faculdade de Direito. São Paulo: FAAP, ano IV, volume 8, 2012, p.22-27.

27 Multilateral Fund for the Implementation of the Montreal Protocol. Disponível em http:// http://www.multilateralfund.org/ default.aspx. Acesso em 20 mai 2017.

28 Artigo 20, do Protocolo de Montreal. 
vigor, automaticamente, sem a necessidade de ratificação individual de cada Parte, conferindo mobilidade institucional ao regime.

Outro instrumento que confere flexibilidade são as isenções de uso crítico, que permitem a acomodação dos interesses, com vistas a uma melhor eficiência, porque permitem uma transição para soluções amigáveis que não causem impacto econômico ou prejuízos à população. As isenções, que podem ser compreendidas como pequenas exceções às restrições do Protocolo, podem ser solicitadas por qualquer Parte quando ainda não há alternativas tecnicamente ou economicamente viáveis para a eliminação da substância ou motivadas por razões de saúde ou segurança ${ }^{29}$.

Importa destacar que essa problemática como outras da agenda global ambiental, são mais dependentes da cooperação entre os Estados e entre outros atores para o seu efetivo enfrentamento e equacionamento, o que é muito mais fácil de se atingir por meio de uma estrutura dinâmica e flexível, preocupada muito mais com a eficiência do que a coerção.

A necessidade da ação de cooperação, ao mesmo tempo em que faz o mundo mais interdependente, o torna mais monitorado, vigiado em relação ao passado, confirmando uma nova lógica de poder e convivência nas relações internacionais ${ }^{30}$, que é indutora da eficiência ambiental.

Não fosse o sucesso obtido com a multilateralidade e ampliação da atuação, em 2050 a destruição da camada teria crescido pelo menos $50 \%$ no hemisfério norte e 70\% no hemisfério sul. O resultado implicaria a emissão do dobro de radiação UV-B alcançando a Terra no hemisfério norte e o quádruplo no sul. A quantidade de substâncias que destroem a camada de ozônio (SDOs) na atmosfera seria dez vezes maior e a implicação disso seria desastrosa, com perspectivas de aproximadamente 20 milhões a mais de casos de câncer e 130 milhões a mais de casos de catarata ${ }^{31}$.

29 Por exemplo, isenções específicas de uso essencial foram concedidas para que países desenvolvidos ainda possam usar CFCs em inaladores, para o tratamento de asma e outras doenças respiratórias crônicas.

30 REI, F.; PINHO, M.L. A contribuição da paradiplomacia ambiental e econômica no regime internacional das mudanças climáticas e sua percepção pelo direito ambiental internacional. In: GRANZIERA, M. L. e REI, F.. Santos: Editora Universitária Leopoldianum, 2017, p. 09.

31 STEINER, Achim. Quatro décadas de desenvolvimento. Bra-
Assim, uma curiosidade que gravita em torno do regime do ozônio vai no sentido de investigar como ele conseguiu tanto avanço em curto espaço de tempo. As metas ajustadas são ambiciosas e o nível geral de cumprimento, por seus membros, é alto, característica não muito comum nos regimes ambientais.

No entanto, se, por um lado, o Protocolo de Montreal é reconhecido, no âmbito do Direito Ambiental Internacional, como um tratado multilateral de sucesso, não se pode esquecer que o esforço de proteção à camada de ozônio ainda enfrenta desafios e, "manter o ímpeto e o financiamento para a eliminação final é crucial para um bom final para esta história inédita de sucesso internacional" 32 , somente atingível por meio da governança global, que será objeto de estudo na próxima sessão.

\section{A CONTRIBUIÇÃo DA GOVERNANÇA GLOBAL NO PROCESSO dE MATERIALIZAÇÃO DO DIREITO AMBIENTAL INTERNACIONAL ANALISADA SOB A ÓTICA DA CONSTRUÇÃO DO REGIME DO OZÔNIO}

As questões e problemas ambientais mais relevantes não se limitam às fronteiras territoriais dos Estados nacionais, extrapolando limites espaciais e temporais, cujo enfrentamento de forma isolada é inviável ou imperceptível. Além disso, a busca de soluções para assuntos ambientais complexos e os arranjos para implementação de medidas necessárias extrapolam a perspectiva do modelo clássico do Direito Internacional, justificando a existência do Direito Ambiental Internacional, como ramo autônomo e independente ${ }^{33}$.

Por seu caráter multidisciplinar, o Direito Ambiental Internacional sofre grande influência de outras ciências, porque exige, para sua construção, a busca de conhecimentos específicos em várias áreas das ciências. A

sil: Nações Unidas, 2012. Disponível em https://nacoesunidas.org/ quatro-decadas-de-desenvolvimento-achim-steiner. Acesso em 29 abr 2017.

32 REI, F.C.F., CARVALHO, S.M. (no prelo). O Protocolo de Montreal sobre substâncias que destroem a camada de ozônio. Coleção Embrapa de Direito Ambiental. Vol. 3.

33 SILVA, Deise Marcelino e REI, Fernando. Direito Internacional do Meio Ambiente (DIMA) e Direito Ambiental Internacional (DAI): Novos atores em cena. Disponível em http://www.publicadireito.com.br/artigos/?cod=16e62507eba0d973. Acesso em 07 dez 2017. 
globalização, o desenvolvimento da tecnologia, os constantes desafios de acomodação do meio ambiente ao crescimento populacional, a busca por desenvolvimento econômico e novos modelos de produção e de consumo em massa conferem esse caráter multidisciplinar ao Direito Ambiental Internacional, distanciando-o do Direito Internacional Público para aproximá-lo muito mais do campo das Relações Internacionais, porque procura buscar novas formas de convivência internacional, preferindo-se os instrumentos institucionais de cooperação em vez de regulação normativa e o sistema tradicional de responsabilização, bem como reconhecendo que outros atores, além dos sujeitos internacionais, podem contribuir para o enfrentamento.

Pela própria natureza e dificuldade de tutela, o Direito Ambiental Internacional é eminentemente participativo e permite que a busca de soluções ambientais possa ser compartilhadas por qualquer ator capaz de contribuir com informações técnicas ou ações criativas e relevantes, isso porque a crise ambiental é de fato global, mas a gestão coletiva transita entre o global e o local ${ }^{34}$.

Embora os Estados sejam os titulares da personalidade internacional capaz de construir o arcabouço normativo ambiental internacional, não são capazes, sozinhos, de enfrentar os problemas ambientais globais, o que os leva a ceder parte de sua soberania, aceitando compartilhar soluções e ampliar o debate com outros atores.

Nesse sentido, a busca de soluções ambientais exige "maior flexibilidade e criatividade na produção, no estudo e na aplicação das normais internacionais", demandando "conjuntos normativos não necessariamente jurídicos"35.

Percebe-se, no âmbito da formulação de normas jurídicas, que a diversidade dos assuntos submetidos à disciplina do Direito Ambiental Internacional acaba acarretando também uma diversidade de normas ambientais que muitas vezes se contrapõem ${ }^{36}$.

34 RAMPASO, Adriana Vinholi; ICHIKAWA, Elisa Yoshie e CARRIERI, Alexandre de Pádua. A influência do Mundo dos Negócios na Governança Ambiental Global. In: Revista de Ciências da Administração, vol. 16, no. 40. Santa Catarina: Universidade de Santa Catarina, 2014, p. 75-89.

35 REI, Fernando. A Peculiar Dinâmica do Direito Internacional do Meio Ambiente. In: Direito Internacional do Meio Ambiente: Ensaios em Homenagem ao Prof. Guido Fernando Silva Soares. Salem Hikmat Nasser e Fernando Rei (Org.). São Paulo: Atlas, 2006.

36 BARROS-PLATIAU, Ana Flávia; VARELLA, Marcelo Dias e SCHLEICHER, Rafael T. Meio Ambiente e Relações Internacionais: perspectivas teóricas, respostas institucionais e novas dimensões
As diretrizes que guiam a questão ambiental são muitas vezes antagônicas àquelas que guiam as questões de ordem econômica, acarretando oposição ou conjunção de interesses em diversos tratados multilaterais, que exigem mecanismos capazes de conferir eficácia ao Direito Ambiental Internacional, somente atingível por meio de gestão inclusiva, tanto na tomada de decisão quanto nos processos de implementação.

Essa constante acomodação entre o aspecto normativo e de implementação induz respostas institucionais e novas dimensões de debate que permitam a interlocução entre atores tão assimétricos, mas, ao mesmo tempo, tão indispensáveis.

A igualdade entre os Estados continua a ser a máxima das relações internacionais e consequentemente do Direito Ambiental Internacional, mas eles não são mais os únicos protagonistas do multilateralismo moderno, estando sujeitos às influências positivas ou negativas dos demais atores, ora a impulsionar compromissos multilaterais ambiciosos, ora funcionando como barreira à cooperação, formando "novos centros de influência global”, que buscam a defesa de demandas e aspirações específicas e muitas vezes diversas dos interesses estatais $^{37}$, criando, por meio de suas interações, diferentes domínios políticos sobrepostos ${ }^{38}$, que precisam ser administrados sem um poder central.

Os Estados começam a enxergar que a diplomacia tradicional não é capaz de enfrentar os novos problemas ambientais, porque há uma desconexão entre a distribuição de autoridade de tomada de decisão e o poder militar, diplomático e econômico dos Estados (assimetrias), estabelecendo uma lacuna entre legitimidade e eficiência ${ }^{39}$, que os demais atores procuram preencher, por meio de uma participação e cobrança assertiva, exigindo voz e vez nos debates internacionais e influenciando substancialmente na construção do jus cogens ${ }^{40}$.

de debate. In: Revista brasileira de Política Internacional, vol. 47, no. 02. Brasília: Instituto Brasileiro de Relações Internacionais, 2004. 37 VAN LANGENHOVE, Luk. Multilateralism 2.0: The Transformation of International Relations, 2011.

38 VAN LANGENHOVE, Luk. The Transformation of Multilateralism Mode 1.0 to Mode 2.0. In: Global Policy, vol. 01, issue 03, 2010, p. 263-270 e RICCI, Alessandra. Multilateralism 2.0: Finding Some Evidence. In: UNU-CRIS Working Papers, W 2014/6, Bélgica, p. 11.

39 THAKUR, Ramesh; VAN LANGENHOVE, Luk. Enhancing Global Governance Through Regional Integration. In Global Governance 12.3, 2006, p. 233-240.

40 BOUCHARD, Caroline; PETERSON, John. Conceptualising Multilateralism - Can we All Just Get Along? MERCURY, E-paper 
O modelo clássico de Direito Internacional não reconhece, juridicamente, essa atuação alargada, razão pela qual o Direito Ambiental Internacional vai procurar acomodar as instituições jurídicas através dos modelos de governança.

Nesse sentido, a governança aparece como um meio de guiar o processo de "enfrentamento da problemática" e pode ser visto como um conjunto de regras, processos e envolvimento de diversos atores para a realização de um objetivo comum ${ }^{41}$.

Governança e regimes concordam sobre a necessidade de cooperação para os interesses compartilhados, que justifica a aceitação desse conjunto de regras e procedimentos, e cuja efetividade não está necessariamente vinculada a uma autoridade central ${ }^{42}$.

No caso específico do regime do ozônio, a mídia e os grupos ambientalistas, na década de 70, desempenharam papel de importância ao trazer a questão da influência antrópica sobre a camada de ozônio ao debate, cobrar uma urgência na agenda internacional, conferindo visibilidade à problemática ${ }^{43}$. O segundo passo que influenciou os ajustes e instrumentos internacionais foram os resultados dos estudos científicos e identificação dos riscos, ressaltando a gravidade e necessidade de se buscarem alternativas para conter a destruição da camada de ozônio, mas é necessário destacar que o regime evoluiu mesmo na ausência de demonstração cientifica da influência da atuação antrópica sobre o ozônio.

O ápice do processo de ampliação participativa foi a proatividade de algumas indústrias multinacionais, que contribui para vencer a resistência estatal e quebrar o lobby industrial contra a eliminação do uso do clorofluorcarbono (CFC). O anúncio da DuPont manifestando interesse em desenvolver pesquisas para encontrar um substituto ao CFC, desde que lhe fosse garantido mercado para o novo produto, seguida por outras grandes empresas multinacionais que visualizaram, na crise

No. 1, 2011, p. 29-31.

41 KEMP, R.; MARTENS, PAG. Sustainable development: how to manage something that is subjective and can never be achieved? Sustainability: science, practice and policy, v. 3, n. 2, 2007.

42 LIMA, Gabriela Garcia Batista. Conceitos de relações internacionais e teoria do direito diante dos efeitos pluralistas da globalização: governança global, regimes jurídicos, direito reflexivo, pluralismo jurídico, corregulação e autorregulação Revista de Direito Internacional, Brasília, v. 11, n. 1, 2014, p. 221.

43 SUNSTEIN, Cass R. Montreal and Kyoto: a tale of two Protocols. John M. Olin Program in Law and Economics Working Paper No. 302, 2006. ambiental, uma oportunidade de inovação e, claro, uma perspectiva de lucro em longo prazo, sacramentou a participação desses novos atores no processo de governança, que com certeza conduziu ao sucesso do regime.

Não fosse o Protocolo de Montreal sinalizar que o mercado de CFC estava destinado a desaparecer, talvez a indústria não tivesse desenvolvido energia criativa necessária a descoberta dos substitutos químicos necessários ${ }^{44}$.

A contribuição de ONGs ambientalistas nas Conferências das Partes, cobrando posições e auxiliando com informações técnicas, construiu o elo de aproximação da sociedade civil das discussões internacionais e o processo participativo também contou com a influência da academia, dos esforços voluntários de governos subnacionais e do dinamismo imposto por organizações internacionais, como o PNUMA e o PNUD, formando uma grande rede de troca de experiências e cooperação multinível ${ }^{45}$.

Esse processo intenso e dinâmico de alargamento da participação e formação da consciência ambiental foi capaz de ampliar o debate internacional para a oportunidade de inserção de novos atores ${ }^{46}$, que está diretamente associada a dois fenômenos marcantes do século XX, o processo de globalização e a emergência de problemas ambientais globais relativos à low politics.

A problemática da destruição da camada de ozônio, assim como as mudanças climáticas ignoram barreiras estatais, seja porque a recomposição ambiental constitui um continum ecológico que se projeta tanto nos espaços submetidos à soberania dos Estados, como mais além destes $^{47}$, seja porque os impactos desses problemas ambientais são, ao fim e ao cabo, sentidos concretamente

44 BENEDICK, Richard Elliot. The Improbable Montreal Protocol: Science, Diplomacy, and Defending the Ozone Layer. Disponível em http://www.ibrarian.net/navon/paper/T_H_E_IMPROBABLE_MONTREAL_PROTOCOL_SCIENCE_DIPL. pdf?paperid=3892539. Acesso em 05 jul 2017, p. 22.

45 SARRO, Vanessa Martins. Os Mecanismos da Governança Global para Proteção da Camada de Ozônio. Dissertação apresentada para obtenção do Título de Mestre em Direito pela Universidade Católica de Santos. Santos: Universidade Católica de Santos, 2016, p. 45.

46 KEOHANE, R. and J.S. NYE, Jr. (Eds). Transnational Relations and World Politics (Cambridge, MA: Harvard University Press), 1971.

47 RUIZ, J.J. "Protection of the Atmospheric Environment by International Law" in KISS, A. Ch. Y Shelton. D (Ed), Manual of European Environmental Law, 2nd.edition, Cambridge: Cambridge University Press, 1997. 
nos níveis infranacionais ${ }^{48}$. A dualidade global-local da destruição da camada de ozônio, também presente nas mudanças climáticas, inculcou o sentido de responsabilidade por seu enfrentamento em todos os níveis de organização social ${ }^{49}$.

Percebe-se que a complexidade da resposta internacional aos problemas globais e a necessidade de ações mais práticas de enfrentamento têm, progressivamente, legitimado o surgimento dessas novas formas de autoridade, como identificado no regime do ozônio. Embora desprovidas dos elementos da soberania, autonomia e controle. Essas novas estruturas ganham uma legitimação voluntária da sociedade ${ }^{50}$, originada a partir do reconhecimento de que o efetivo enfrentamento das questões ambientais globais necessita da ação cooperada e coordenada de sistemas de governança baseados em diversos níveis (estatais, supra, infra e interestatais) e compostos por atores estatais, infraestatais (regionais e locais) e não governamentais, cada um desempenhando uma variedade de papéis ${ }^{51}$. Fala-se, nesse caso, de uma nova governança ambiental global.

O encaminhamento dessa resposta internacional passa, então, pela ação e articulação de múltiplos atores, porque são problemas em que a posição de poder não consegue encaminhar adequadamente soluções, já que na construção da governança ambiental global a cooperação e a negociação pressupõem a participação ampliada na construção do consenso ${ }^{52}$.

Diante, portanto, de uma ordem mundial destituída de poderes hegemônicos ${ }^{53}$, a governança se legitima

48 BODANSKY, D. The legitimacy of international governance: a coming challenge for international environmental law? The American Journal of International Law - vol.93, n.3, jul., 1999, p. 596-624.

49 LITFIN, K.T. Environment, Wealth and Authority: global climate change and emerging modes of legitimation. International Studies Review, vol.2, n. 2, 2000, p. 119-148.

50 DEDUERWAERDERE, T. The contribution of network governance to sustainable development. Belgique: Université Catholique de Louvain Fonds National de la Recherche Scientifique, 2005.

51 Bulkeley, H. and BETSILL, M.M. Cities and Climate Change: Urban Sustainability and Global Environmental Governance. London: Routledge, 2003.

52 FARIAS, Valéria Cristina e REI, Fernando. Reflexos jurídicos da governança global subnacional - A paradiplomacia e o Direito Internacional: desafio ou acomodação. Brasília: Revista de Direito Internacional, v. 13, n. 1, 2016, p. 330-333.

53 STEIN, Arthur A. Structural Perspectives: Coordination and collaboration: regimes in an anarchic world. In: KRASNER, Stephen D. International Regimes. Ithaca/London: Cornell University Press, 1983. como instrumento de solução de problemas ${ }^{54}$, inviabilizando a lógica de um Direito Internacional fundado na coerção, no monopólio da força e na ação diplomática e justificando a inter-relação com o Direito Ambiental Internacional.

Além disso, problemas globais, como a questão da proteção à camada de ozônio, não encontram solução adequada ou encaminhamento possível dentro dos mecanismos tradicionais do Direito Internacional Público, como o mecanismo da responsabilidade por dano ambiental causado por ato ilícito, ou mesmo lícito, fundada no nexo causal.

Em outras palavras, a partilha das responsabilidades por emissões de substâncias que destroem a camada de ozônio (SDOs) e os esforços de eliminação e substituição dessas substâncias não está ao alcance de um tribunal internacional ou de um organismo supraestatal, muito menos no uso da força. As soluções ambientais dependem de avanços tecnológicos, de investimentos do capital, da mudança de hábitos e padrões de produção e consumo obtidos com maior propriedade no aprimoramento dos regimes internacionais do que sob o manto da responsabilidade internacional ${ }^{55}$.

No regime internacional de proteção à camada de ozônio, as partes buscam, por intermédio da negociação, tomar decisões consensuais que ditam princípios, regras e diretrizes que orientam o comportamento das próprias partes, com vistas a atingir objetivos previamente definidos, como a recuperação da camada de ozônio. Nesse extenso processo dialógico internacional, se admite e se estimula a participação de todos os sujeitos relevantes, estatais e não estatais, para o enfrentamento do problema real e concreto, porque essa participação é indispensável para a condução de sucesso do regime.

Bem que se diga que, atualmente, o processo de ampliação da participação das discussões globais não é exclusividade do regime de ozônio, mas é possível afirmar que por meio dele se concretizou a construção da visão de cooperação multinível como processo capaz de conduzir à eficiência ambiental.

A agenda global vem se ampliando nas últimas dé-

54 ROSENAU, James N. \& CZEMPIEL, Ernst-Otto. Governance without Government: Order and Change in World Politcs. Cambridge: Cambridge University Press, 2000.

55 GERENT, Juliana. Conflitos Ambientais Globais: Mecanismos e Procedimentos para a solução de controvérsias, Curitiba: Editora Juruá, 2016, p. 229-237. 
cadas e incluindo questões que não se limitam apenas a high politics, como é o caso das mudanças climáticas, biodiversidade, refugiados e que acabam influenciando a diplomacia multilateral, trazendo para o debate político outros atores diversos dos Estados.

Essa tendência ao alargamento das discussões internacionais confunde o multilateralismo tradicional, que assume um contorno moderno e diverso ${ }^{56}$, mas que acaba por exprimir novos modelos de desenvolvimento da governança que impulsionam compromissos multilaterais ambiciosos, através de uma participação assertiva, cobranças pontuais, troca de experiências e outros componentes da interação público-particular que prioriza e conduz as aspirações proativas.

Essa transformação do sistema internacional, que antes era fechado e restrito aos Estados e organizações internacionais, em um sistema internacional aberto, que se desenvolve por meio de vários níveis de governança, interdependentes entre $\mathrm{si}^{57}$, influencia e enriquece o processo decisório, porque enquanto a legitimidade para firmar acordos envolvendo problemas globais está concentrada nos Estados, as fontes e possíveis soluções se situam no nível transnacional ou regional ${ }^{58}$.

Por meio da governança ambiental global, diferentes formas e níveis de enfrentamento dos problemas ambientais passam a coexistir numa dinâmica de complementaridade, de tal forma que o avanço dos regimes internacionais baseados em tratados multilateralmente firmados é fortalecido e fomentado pelas iniciativas desenvolvidas nos níveis infra e transnacionais e por atores ainda não formalmente partes do sistema jurídico internacional.

Com a evolução da ciência atmosférica, viu-se reforçado o caráter universal da destruição da camada de ozônio, seja porque suas causas antrópicas estavam no cerne do então modelo de produção e consumo das SDOs, seja porque a gravidade de seus impactos foi percebida em todos os níveis da sociedade - do local ao global —, e sob as diferentes nuances - ambientais,

56 VAN LANGENHOVE, Luk. "Multilateralism 2.0: The Transformation of International Relations", 2011.

57 RICCI, Alessandra. Multilateralism 2.0: Finding Some Evidence. UNU-CRIS Working Papers, W 2014/6, Belgica.

58 THAKUR, Ramesh. The United Nation in Global Governance. Disponível em http://www.un.org/en/ga/president/65/initiatives/GlobalGovernance/Thakur_GA_Thematic_Debate_on_ UN_in_GG.pdf. Acessado em 10 de maio de 2017. médicas, sociais, econômicas e políticas ${ }^{59}$.

A materialização do princípio da precaução aflorado nos ajustes do regime do ozônio, a contribuição valorosa dos demais atores internacionais e o equacionamento, em curto espaço de tempo, desse complexo problema global revela-se e precisa ser destacada como uma grande conquista do Direito Ambiental Internacional, levada a efeito sob o manto da governança global e que permite infirmar a inter-relação e importância da governança no processo de criação e desenvolvimento do Direito Ambiental Internacional.

No entanto, ressalte-se que, enquanto nos anos 80 o buraco da camada de ozônio ganhou repercussão internacional, a partir da década de 90, a preocupação passou a girar em torno do aquecimento global e mudanças climáticas causados pelos gases de efeito estufa e, cumpre salientar, a sociedade tem muito conhecimento sobre o Protocolo de Kyoto e o Acordo de Paris e quase nenhum sobre o de Montreal ${ }^{60}$, o que é curioso, visto a estreita relação entre os regimes, que será objeto de estudo na próxima seção.

\section{A Emenda de Kigali: Sinergia dos regimes DO OZÔNIO E MUDANÇA CLIMÁTICA}

Embora a destruição da camada de ozônio e o aquecimento global sejam fenômenos naturais diversos, existem algumas conexões entre eles. $\mathrm{O}$ aquecimento global é um aumento da temperatura média da Terra que decorre, basicamente, do acúmulo de gases de efeito estufa, por um processo natural de aquecimento e resfriamento da superfície global, mas que vem sendo intensificado pelo acúmulo antrópico de dióxido de carbono, metano e outras substâncias capazes de reter o calor nas camadas baixas da atmosfera. Embora de forma modesta, o aquecimento global interfere na destruição da camada de ozônio, principalmente na Antártica, pois "os gases de cloro na estratosfera inferior interagem com partículas de nuvem que se formam a temperaturas extremamente baixas". Como o ozônio

59 REI, F.C.F., CARVALHO, S.M. (no prelo). O Protocolo de Montreal sobre substâncias que destroem a camada de ozônio. Coleção Embrapa de Direito Ambiental. Volume 3.

60 SILVA, Darly Henriques da. Protocolos de Montreal e Kyoto: pontos em comum e diferenças fundamentais. Brasília: Revista Brasileira de Política Internacional, vol. 52, no. 02, 2009. 
na estratosfera absorve o calor, o comprometimento da camada de ozônio também intensifica o aquecimento global. No mais, o CFC e seus substitutos, além de serem uma substância que destroem a camada de ozônio, também contribuem para o efeito estufa e, reflexamente, para o aquecimento global ${ }^{61}$.

Todos esses fatores permitem concluir que existe uma linha bastante comum nos esforços multilaterais tendentes à tutela da camada de ozônio e das mudanças climáticas. No entanto, se as razões científicas apresentam um denominador comum, as questões político-econômicas distanciam o enfrentamento internacional ${ }^{62}$ e a cooperação entre os regimes é contenciosa.

Os painéis de avaliação técnica e científica ${ }^{63}$ sob os regimes de proteção à camada de ozônio e às mudanças climáticas também observaram que a queda global nas emissões de substâncias que destroem a camada de ozônio (SDO) gerou reduções nas emissões de gases de efeito estufa (GEE) equivalentes a bilhões de toneladas de CO2. Segundo o mesmo informe, os Estados-parte do Protocolo de Montreal já eliminaram cerca de 98\% de substâncias nocivas para a camada de ozônio, impedindo, assim, que mais de dois milhões de casos de câncer de pele atingissem a população por ano.

Essas reduções confirmam o papel desempenhado pelo Protocolo de Montreal como um importante colaborador na luta global não somente em relação às emissões de substâncias que destroem a camada de ozônio (SDOs), como em relação às emissões de gases de efeito estufa (GEE), que influenciam as mudanças climáticas e respondem a regime próprio.

Como algumas substâncias que destroem a camada de ozônio (SDOs) também têm altíssimo potencial de aquecimento global, a eliminação geral de SDOs no mundo todo pode gerar benefícios sinérgicos em relação ao enfrentamento do aquecimento global, o que demonstra a interação entre os regimes do ozônio e das mudanças climáticas. Dessa forma, é possível afirmar que a eliminação das substancias que destroem a camada de ozônio (SDOs) obtida até o momento está resultan-

61 REBECCA, Lindsey. O buraco da camada de ozônio e o aquecimento global. Disponível em http://cienciasclimaticas.blogspot.com.br/2010/09/o-buraco-da-camada-de-ozonio-e-o.html. Acesso em 10 jul 2017.

62 SILVA, Darly Henriques da. Protocolos de Montreal e Kyoto: pontos em comum e diferenças fundamentais. Brasília: Revista Brasileira de Política Internacional, vol. 52, no. 02, 2009, p. 03.

63 UNEP, 2009. do não somente na regeneração da camada de ozônio, mas também em importantes reduções nas emissões de gases de efeito estufa.

Tendo em vista o imenso potencial de mitigação das mudanças climáticas que uma eliminação acelerada dos hidroclorofluorcarbonos (HCFCs) poderia trazer, o diálogo sobre os HCFCs evoluiu, consideravelmente, desde 2005. Isso porque, embora não sejam nocivos à camada de ozônio ${ }^{64}$, são gases de efeito estufa com potencial muito superior ao dióxido de carbono (CO2). Em razão disso, propostas de ajuste do Protocolo com a adoção de metas interinas foram tabuladas para serem analisadas pelas Partes. A intensa negociação diplomática foi exitosa e o Protocolo vem sendo ajustado por consenso.

Ao longo dos anos e graças à estrutura até então desconhecida das Convenções Quadro, o regime internacional de proteção à camada de ozônio foi sendo ajustado, fosse para introduzir outros tipos de medidas de controle, acrescentar novas substâncias controladas para a lista, fosse para acelerar os cronogramas de eliminação progressiva. Essas alterações ao Protocolo de Montreal são nomeadas de acordo com o local de sua adoção: Londres (1990), Nairóbi (1991), Copenhagen (1992), Bangkok (1993), Viena (1995), Montreal (1997), Pequim (1999) e, mais recentemente, Kigali (outubro, 2016).

Em resposta ao Acordo de Paris de 2015, em contribuição direta ao regime internacional de mudanças climáticas, a Emenda de Kigali — que estabelece o controle do consumo dos hidrofluorcarbonos (HFCs) pelo Protocolo de Montreal — representou outro grande fato histórico, pois, pela primeira vez, o Protocolo passou, também, a tratar de substâncias que não causam danos à camada de ozônio, mas que afetam o sistema climático global, reconhecendo-se a sinergia dos regimes.

Se, anteriormente, o Protocolo de Montreal estava debruçado apenas sobre o controle de substâncias capazes de comprometer a camada de ozônio, a partir de Kigali, ganhou nova roupagem para admitir outras estratégias capazes de controlar o forçamento climático.

A inclusão dos HFCs na relação de gases proibidos produz um efeito positivo na contenção do aquecimento global, facilitando o cumprimento das metas assumi-

64 Os HFCs foram adotados em substituição aos CFCs, como alternativa menos impactante à camada de ozônio. 
das no Acordo de Paris, que restringiu o aumento da temperatura média da terra entre 1,5 e 2 graus Celsius, neste século, tomando-se por base os níveis pré-Revolução Industrial, estimando-se que a medida adotada em Kigali poderá evitar em até 0,5 grau Celsius o aquecimento global.

Essa interconexão é extremamente importante, porque permite agregar o grau de eficiência do regime do ozônio à busca do ideal de controle das emissões de gases de efeito estufa no combate às mudanças do clima e o diálogo entre os regimes, com certeza, distinguirá e impulsionará avanços futuros, trazendo benefícios ambientais únicos.

No entanto, é preciso destacar que ainda resta ao regime o desafio de eliminar todas as SDOs, ressaltando-se que gases alternativos mais comuns, como os hidroclorocarbonos (HCFC), perfluorocarbonos (PFC) e halocarbonetos, embora não agridam o ozônio, são extremamente nocivos à saúde climática do planeta ${ }^{65}$.

Além disso, idealizando-se uma perfeita sinergia entre os regimes e aproveitando-se o dinamismo e flexibilidade do ajuste de ozônio, poder-se-ia cogitar eventual inclusão de padrões restritivos de emissões de carbono e metano às atividades industriais, ampliando-se o escopo do Protocolo de Montreal, sem que isso importe em desvio de finalidade, pois demonstrada a estreita relação entre a depleção da camada de ozônio e o aquecimento global.

Tal medida seria plenamente possível se realizada sob a forma de emenda, pois os artigos 20 e 21 do Protocolo de Montreal preveem e admitem emendas ao protocolo em si ou seus anexos, exigindo-se decisão por consenso, mas admitindo, na sua falta, a aprovação por maioria de três quartos dos votos das Partes presentes e votantes na sessão. O único inconveniente, na hipótese, é que a vinculação dessas emendas fica condicionada à posterior aceitação formal pelos respectivos membros.

A abertura trazida pela inclusão dos HFCs, na emenda de Kigali, pode ser um indicador favorável a essa sinergia, ainda que restrições econômicas decorrentes do uso e exploração de combustíveis fósseis possam prejudicar a cooperação.

65 IPCC. Safeguarding the Ozone Layer and the Global Climate System: Issues Related to Hydrofluorocarbons and Perfluorocarbons. Summary for Policymakers, p. 07. Disponível em https:// www.ipcc.ch/report/sroc/. Acesso 15 mai 2017.
Ademais, o regime do ozônio, no curto período de existência, conseguiu desenvolver estratégias de cooperação internacional porque adotou protocolo restritivo, o que não se observa no regime climático cuja fixação de metas, obrigação de fiscalização e os mecanismos econômicos adotados não foram suficientes para induzir eficiência.

Os gás carbônico e gás metano controlados pelo regime de mudança climática são, em longa escala, produzidos no processo industrial, em que a reestruturação e adaptação tecnológica permitem um controle muito mais fácil do que nos demais setores impactantes como a utilização do solo, desmatamento e queimada ${ }^{66}$.

Dessa forma, assim como a mudança dos processos industriais foi indispensável para a redução das SDOs, a busca de tecnologia para o controle das emissões de gás carbônico e metano pode sinalizar uma alternativa exitosa no futuro, com benefícios não somente ambientais como também econômicos.

Da mesma forma que a substituição do CFC proporcionou vantagens econômicas pelo marketing que envolveu a utilização de etiquetas que sinalizavam produtos menos impactantes, mobilizando consumidores conscientes e estimulando vendas e assim como nas tratativas do Protocolo de Montreal, em que a resistência econômica foi abrandada pela evolução científica, perspectiva de lucro e financiamento internacional, as restrições relativas aos demais gases substitutos, emissões de carbono e metano podem seguir o mesmo caminho, prevendo-se períodos de transição, isenções de uso crítico, instrumentos de compensação econômica e outros ajustes de flexibilização capazes de acomodar os interesses conflitantes ou, pelo menos, instigar a discussão e amadurecimento da questão no cenário internacional, permitindo o desenvolvimento da governança.

A modificação e modernização dos procedimentos industriais, a adoção de opções tecnológicas na geração de energia e eficiência energética, utilização de energia alternativa em substituição aos combustíveis fósseis, cogeração de energia, reciclagem, economia de materiais e tratamento do lixo industrial para aproveitamento do metano são exemplos factíveis e capazes de reduzir as emissões do setor industrial e agregar, concomitantemente, benefícios climáticos e à camada de ozônio.

66 SILVA, Darly Henriques da. Protocolos de Montreal e Kyoto: pontos em comum e diferenças fundamentais. Brasília: Revista Brasileira de Política Internacional, vol. 52, no. 02, 2009, p. 13. 
Portanto, ao longo dos trinta anos de existência, o Protocolo de Montreal deve ser reconhecido como uma dinâmica multilateral de sucesso, mas precisa e deve evoluir no potencial regulatório climático, porque o adicional de atenuação do aquecimento global decorrente de adoções restritivas em relação a determinados gases será significativo não somente para evitar a depleção da camada de ozônio, mas principalmente contribuir para o controle da temperatura média da Terra ${ }^{67}$.

Estabelecer interfaces entre objetivos econômicos, sociais e proteção ambiental, embora possa aflorar aspectos conflitantes na seara internacional, é a "essência da dimensão ambiental do desenvolvimento" deve ser perseguida pela comunidade internacional. Além disso, "os objetivos do desenvolvimento sustentável têm essa finalidade de proporcionar a convergência de esforços em determinadas temáticas" ${ }^{" 69}$, justificando e recomendando a sinergia de regimes.

\section{Considerações finais}

Após os sinais de alerta descobertos no final dos anos $80 \mathrm{com}$ a descoberta de um grande buraco na camada de ozônio sobre a Antártida, o mundo decidiu agir, com o que se poderia chamar de primeira idade da Governança Global e do Direito Ambiental Internacional, fazendo com que Estados, Empresas Multinacionais, ONGs e outros atores enfrentassem em conjunto o problema, incorporando incertezas científicas e avançando na busca de um enfrentamento não pautado necessariamente pela lógica de negociação do então Direito Internacional do Meio Ambiente.

Após as negociações da Convenção de Viena, o

67 MOLINA, Mario; ZAELKE, Durwood; SARMA, K. Madhava; ANDERSEN, Stephen O.; RAMANATHAN, Veerabhadran; KANIARU, Donald. Reducing abrupt climate change risk using the Montreal Protocol and other regulatory actions to complement cuts in CO2 emissions. Oxford: Environmental Change Institute, 2009, p. 01-06.

68 KIRSCH, Heitor Marcos e FILIPPE, Eduardo Ernesto. A dimensão ambiental do desenvolvimento: implicações para além do seu gerenciamento técnico-administrativo num contexto de mudança climática. Brasília: Revista de Direito Internacional, v. 09, n. 3, 2012, p. 29-44.

69 DENNY, Danielle Mendes Thame; DE CASTRO, Douglas; MACHADO, Alexandre Ricardo, MACHADO FILHO, José Valverde e WITT, Gabrielle Fontes. Segurança alimentar e a governança econômica global. Brasília: Revista de Direito Internacional, v. 14, n. 1, 2017, p. 138.
Protocolo de Montreal conduziu a comunidade internacional à eliminação escalonada na produção de clorofluorcarbonos, sendo certo que as previsões da época indicavam que até 2065 , a camada de ozônio estaria reduzida a dois terços de seu tamanho.

No entanto, esse modelo dinâmico de enfrentamento das questões globais fez com que as projeções mudassem e, atualmente, a ONU calcula que, entre 2060 e 2075, a camada de ozônio terá retornado ao mesmo nível dos anos 80.

Os resultados desses 30 anos de existência do Protocolo mostram a importância de o regime internacional seguir avançando com ações para a proteção da camada de ozônio por meio de um bem-sucedido modelo de governança.

Nesse esforço global, merece destaque o papel do Direito Ambiental Internacional, com suporte fundamental de programas do sistema das Nações Unidas, como o PNUMA e PNUD, e com o braço financeiro do Fundo Multilateral, que soube incorporar numa estrutura de convenção quadro, emendas, ajustes, informes técnicos que lograram obter resultados concretos de eficácia e eficiência, porque permitiram uma arquitetura dinâmica e flexível.

Dito de outra forma, uma estrutura de governança adequada foi capaz de levar em conta os interesses dos diferentes atores envolvidos, ao mesmo tempo proporcionando o alcance da solução ambiental (eficácia) de forma eficiente, equitativa e legitimada por um law making process compatível com os valores de uma sociedade global.

Em suma, o Protocolo de Montreal, o único tratado multilateral que obteve ratificação universal, contando com 197 partes, caminha no sentido de atingir a eficácia com o restabelecimento da camada de ozônio em futuro próximo e permite ser destacado como exemplo exitoso no cumprimento do Direito Ambiental Internacional.

Os esforços contínuos de novos atores dessa governança para implementar em rede estratégica o Protocolo demonstram que as difíceis questões envolvendo o binômio interesse econômico/tutela ambiental podem ser enfrentadas e solucionadas de forma igualitária e sustentável, com base regulatória, principalmente quando enfrentadas num espaço de cooperação, diálogo com o setor produtivo, estímulo pautado pelo avanço científico, tecnológico e financeiro, sem ignorar a participação de novos atores globais. 
O enfrentamento da problemática da destruição da camada de ozônio não foi e não é uma preocupação exclusiva dos Estados e, durante esses 30 anos, atores privados se envolveram na busca de soluções para a problemática. A participação direta e a diversificação dos atores privados na governança do ozônio são consideradas precursoras de um fenômeno de caráter transnacional que hoje envolve outros regimes, concretizando a construção da visão de cooperação multinível como processo capaz de conduzir à eficiência ambiental e situando, no âmbito dos regimes, o melhor instrumento de solução dos conflitos do Direito Ambiental Internacional.

Mas, como nem tudo são flores, é preciso destacar que o Protocolo de Montreal e suas emendas é exitoso no sentido de evitar a depleção do ozônio, mas interfere no aquecimento global. Além disso, as emissões de gases de efeito estufa (muitos deles utilizados como substituto ao CFC), entre eles o gás carbônico e gás metano, também são agentes impactantes ao ozônio, recomendando uma abordagem de tutela holística.

Diante da correlação entre as questões climáticas e a depleção do ozônio, a busca de mecanismos que possibilitem a coordenação entre os dois regimes internacionais significaria um caminho promissor em termos ambientais.

A emenda de Kigali, adotada logo após e sob a influência benéfica do Acordo de Paris, possibilitou um início de sinergia entre os regimes do ozônio e de mudança do clima, alargando o escopo restritivo do Protocolo de Montreal, mas ainda não é o ideal, porque outros gases utilizados como alternativa do CFC intensificam o efeito estufa.

A dependência econômica dos combustíveis fósseis e a dificuldade de mudança nos modos de produção industrial ainda são questões que precisam ser enfrentadas e que afetam não apenas o clima, mas, indiretamente, a camada de ozônio e, especialmente em relação ao gás carbônico e gás metano, extremamente indutores do aquecimento global, sendo certo que a solução não é tão simples quanto substituir um produto ou uma substância por outra.

Assim, apesar de ser considerado um êxito, a evolução do regime do ozônio pressupõe a continuidade de negociações, a busca incessante por novas práticas, pela troca multilateral, pela cooperação multinível e principalmente o diálogo com outros regimes que fo- ram indispensáveis na construção de uma estrutura própria e peculiar, distinguindo-o como um exemplo e modelo de eficiência que não deve estagnar, porque o enfrentamento internacional é diretamente dependente da evolução das habilidades da produção econômica e uma economia de desenvolvimento é aquela que gravita entre o social e o privado com equilíbrio e respeito ao meio ambiente.

É perfeitamente possível alargar o escopo restritivo do Protocolo de Montreal sem que se abandone a sua finalidade, cingindo ou associando a tutela do ozônio à proteção do clima, para que possa continuar desempenhando sua função de acordo ambiental multilateral mais importante e eficiente da história.

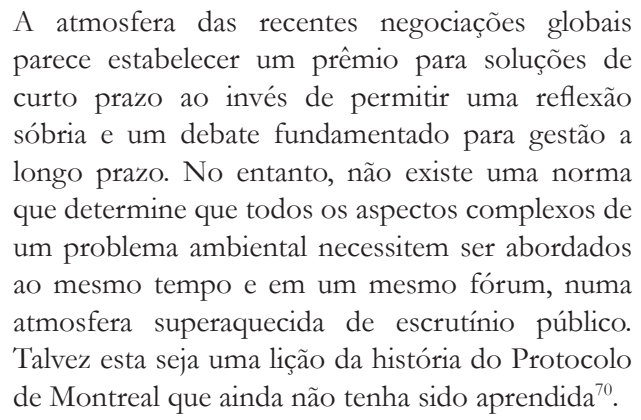

\section{REFERÊNCIAS}

ANTEQUERA, J. Conde. Responsabilidad y restauración ambiental por riesgos del desarrollo. In ALONSO, E. Pérez; GARCÍA, E. Arana; PACHECO, P. Mercado; MORENO, J.L. Serrano (eds). Derecho, Globalización, Riesgo y Medio Ambiente. Valencia: Tirant lo Blanch. 2012, p. 498.

BARROS-PLATIAU, Ana Flávia; VARELLA, Marcelo Dias e SCHLEICHER, Rafael T. Meio Ambiente e Relações Internacionais: perspectivas teóricas, respostas institucionais e novas dimensões de debate. In: Revista Brasileira de Política Internacional, vol. 47, no. 02. Brasília: Instituto Brasileiro de Relações Internacionais, 2004.

BENEDICK, Richard Elliot. The Improbable Montreal

70 BENEDICK, Richard Elliot. The Improbable Montreal Protocol: Science, Diplomacy, and Defending the Ozone Layer. Disponível em http://www.ibrarian.net/navon/paper/T_H_E_IMPROBABLE_MONTREAL_PROTOCOL_SCIENCE_DIPL. pdf?paperid=3892539. Acesso em 05 jul 2017, p. 23 - tradução própria. 
Protocol: Science, Diplomacy, and Defending the Ozone Layer. Disponível em http://www.ibrarian.net/navon/ paper/T_H_E_IMPROBABLE_MONTREAL_PROTOCOL_SCIENCE_DIPL.pdf?paperid $=3892539$. Acesso em 05 jul 2017.

BODANSKY, D. The legitimacy of international governance: a coming challenge for international environmental law? The American Journal of International Law - vol. 93, n. 3, jul., 1999, p. 596-624.

BOUCHARD, Caroline; PETERSON, John. Conceptualising Multilateralism - Can we All Just Get Along? MERCURY, E-paper No. 1, 2011

BULKELEY, H. and BETSILL, M.M. Cities and Climate Change: Urban Sustainability and Global Environmental Governance. London: Routledge, 2003.

DEDUERWAERDERE, T. The contribution of network governance to sustainable development. Belgique: Université Catholique de Louvain Fonds National de la Recherche Scientifique, 2005.

DENNY, Danielle Mendes Thame; DE CASTRO, Douglas; MACHADO, Alexandre Ricardo, MACHADO FILHO, José Valverde e WITT, Gabrielle Fontes. Segurança alimentar e a governança econômica global. Brasília: Revista de Direito Internacional, v. 14, n. 1, 2017, p. 126-141.

EPA- U.S. Environmental Protection Agency. Achievements in Stratospheric Ozone Protection - Progress Report 1987 - 2007, EPA Publication EPA-430-R-07-001.

FARIAS, Valéria Cristina e REI, Fernando. Reflexos jurídicos da governança global subnacional - A paradiplomacia e o Direito Internacional: desafio ou acomodação. Brasília: Revista de Direito Internacional, v. 13, n. 1, 2016, p. 320-339.

GERENT, Juliana. Conflitos Ambientais Globais: Mecanismos e Procedimentos para a solução de controvérsias, Curitiba: Editora Juruá, 2016.

INTERGOVERNMENTAL PANEL ON CLIMATE CHANGE. Safeguarding the Ozone Layer and the Global Climate System: Issues Related to Hydrofluorocarbons and Perfluorocarbons. Cambridge: 2005. Disponível em http:// https://www.ipcc.ch/report/ $\operatorname{sroc} /$.

KEMP, R.; MARTENS, PAG. Sustainable development: how to manage something that is subjective and can never be achieved? Sustainability: science, practice and policy, v. 3, n. 2, 2007.

KEOHANE, R. and J.S. NYE, Jr. (Eds). Transnational Relations and World Politics (Cambridge, MA: Harvard University Press), 1971.

KIRSCH, Heitor Marcos e FILIPPE, Eduardo Ernesto. A dimensão ambiental do desenvolvimento: implicações para além do seu gerenciamento técnico-administrativo num contexto de mudança climática. Brasília: Revista de Direito Internacional, v. 09, n. 3, 2012, p. 29-44.

LIMA, Gabriela Garcia Batista. Conceitos de relações internacionais e teoria do direito diante dos efeitos pluralistas da globalização: governança global, regimes jurídicos, direito reflexivo, pluralismo jurídico, corregulação e autorregulação Revista de Direito Internacional, Brasília, v. 11, n. 1, 2014, p. 215-228.

LITFIN, K.T. Environment, Wealth and Authority: global climate change and emerging modes of legitimation. International Studies Review, vol.2, n. 2, 2000, p.119148.

MOLINA, Mario; ZAELKE, Durwood; SARMA, K. Madhava; ANDERSEN, Stephen O.; RAMANATHAN, Veerabhadran; KANIARU, Donald. Reducing abrupt climate change risk using the Montreal Proto$\mathrm{col}$ and other regulatory actions to complement cuts in $\mathrm{CO} 2$ emissions. Oxford: Environmental Change Institute, 2009.

MULTILATERAL FUND FOR THE IMPLEMENTATION OF THE MONTREAL PROTOCOL. Disponível em http:// http://www.multilateralfund.org/ default.aspx. Acesso em 20 mai 2017.

PETERS, A.; KOECHLIN, L.; FÖRSTER. T. Nonstate actors as standard setters. Cambridge University Press, 2009.

PROTOCOLO DE MONTREAL. A Camada de Ozônio e o risco ao planeta: compromissos assumidos. Disponível em http://www.protocolodemontreal.org. br/eficiente/sites/protocolodemontreal.org.br/pt-br/ site.php?secao $=$ noticias\&pub $=151$.

RAMPASO, Adriana Vinholi; ICHIKAWA, Elisa Yoshie e CARRIERI, Alexandre de Pádua. A influência do Mundo dos Negócios na Governança Ambiental Global. In: Revista de Ciências da Administração, vol. 16, no. 40. Santa Catarina: Universidade de Santa Catarina, 2014, p. 75-89.

REBECCA, Lindsey. O buraco da camada de ozônio 
e o aquecimento global. Disponível em http://cienciasclimaticas.blogspot.com.br/2010/09/o-buraco-da-camada-de-ozonio-e-o.html. Acesso em 10 jul 2017.

REI, F.C.F., CARVALHO, S.M. 25 anos do protocolo de Montreal sobre substâncias que destroem a camada de Ozônio: a experiência do Brasil. Revista Juris da Faculdade de Direito. São Paulo: FAAP, ano IV, volume 8, 2012, p. 22-27

(no prelo). O Protocolo de Montreal sobre substâncias que destroem a camada de ozônio. Coleção Embrapa de Direito Ambiental. Volume 3 .

REI, F.; PINHO, M.L. A contribuição da paradiplomacia ambiental e econômica no regime internacional das mudanças climáticas e sua percepção pelo direito ambiental internacional. In: GRANZIERA, M. L. e REI, F.. Santos: Editora Universitária Leopoldianum, 2017.

REI, Fernando. A Peculiar Dinâmica do Direito Internacional do Meio Ambiente. In: Direito Internacional do Meio Ambiente: Ensaios em Homenagem ao Prof. Guido Fernando Silva Soares. Salem Hikmat Nasser e Fernando Rei (Org.). São Paulo: Atlas, 2006.

RICCI, Alessandra. Multilateralism 2.0: Finding Some Evidence. UNU-CRIS Working Papers, W 2014/6, Belgica.

ROSENAU, James N. \& CZEMPIEL, Ernst-Otto. Governance without Government: Order and Change in World Politcs. Cambridge: Cambridge University Press, 2000 .

RUMMEL-BULSKA, I. "The Protection of the Ozone Layer under the Global Framework Convention" in Transboundary Air Pollution, Dordrecht: Nijhoff, 1988.

RUIZ, J.J. "Protection of the Atmospheric Environment by International Law". In: KISS, A. Ch. Y Shelton. D (Ed), Manual of European Environmental Law, 2nd. edition, Cambridge: Cambridge University Press, 1997.

SARRO, Vanessa Martins. Os Mecanismos da Governança Global para Proteção da Camada de Ozônio. Dissertação apresentada para obtenção do Título de Mestre em Direito pela Universidade Católica de Santos. Santos: Universidade Católica de Santos, 2016.

SECRETARIA DO MEIO AMBIENTE DO ESTADO DE SÃO PAULO. Entendendo o Meio Ambiente: Convenção de Viena para a Proteção da Camada de Ozônio e Protocolo de Montreal sobre Substâncias que
Destroem a Camada de Ozônio. Volume V. São Paulo, 1997.

SILVA, Darly Henriques da. Protocolos de Montreal e Kyoto: pontos em comum e diferenças fundamentais. Brasília: Revista Brasileira de Política Internacional, vol. 52, no. 02, 2009.

SILVA, Deise Marcelino e REI, Fernando. Direito Internacional do Meio Ambiente (DIMA) e Direito Ambiental Internacional (DAI): Novos atores em cena. Disponível em http://www.publicadireito.com.br/ artigos/?cod=16e62507eba0d973. Acesso em $07 \mathrm{dez}$ 2017.

STEIN, Arthur A. Structural Perspectives: Coordination and collaboration: regimes in an anarchic world. In: KRASNER, Stephen D. International Regimes. Ithaca/ London: Cornell University Press, 1983.

STEINER, Achim. Quatro décadas de desenvolvimento. Brasil: Nações Unidas, 2012. Disponível em https:/ / nacoesunidas.org/quatro-decadas-de-desenvolvimento-achim-steiner. Acesso em 29 abr 2017.

SUNSTEIN, Cass R. Montreal and Kyoto: a tale of two Protocols. John M. Olin Program in Law and Economics Working Paper No. 302, 2006.

THAKUR, Ramesh. The United Nation in Global Governance. Disponível em http://www.un.org/en/ga/ president/65/initiatives/GlobalGovernance/Thakur_ GA_Thematic_Debate_on_UN_in_GG.pdf. Acessado em 10 de maio de 2017.

THAKUR, Ramesh; VAN LANGENHOVE, Luk. Enhancing Global Governance Through Regional Integration. In Global Governance 12.3, 2006, p. 233-240.

The Nobel Prize in Chemistry 1995. Press Releasy. The ozone layer - The Achilles heel of the biosphere, 1995. Disponível em https://www.nobelprize.org/nobel_prizes/chemistry/laureates/1995/press.html.

UNDP-United Nations Development Programme. Governance for Sustainable Human Development: A UNDP Policy Document. UNDP, 1997.

UNEP-United Nations Environment Programme. Collaborating on Climate Change - Ozone and Global Warming Experts Get Closer on Common Challenge of F-Gases.2009.

Disponível em http://www.unepag.org/Documents. Multilingual/Default.asp?DocumentID=593\&Article 
ID=6250 >. Acesso em: 1 março de 2017.

VAN LANGENHOVE, Luk. "Multilateralism 2.0: The Transformation of International Relations", 2011.
The Transformation of Multilateralism

Mode 1.0 to Mode 2.0. In: Global Policy, vol. 01, issue 03, 2010, p. 263-270. 
Para publicar na Revista de Direito Internacional, acesse o endereço eletrônico www.rdi.uniceub.br ou www.brazilianjournal.org.

Observe as normas de publicação, para facilitar e agilizar o trabalho de edição. 